\title{
Individual, Age and Sex Differences in Fiber Type Composition of Slow and Fast Muscles of Adult Lewis Rats: Comparison With Other Rat Strains
}

\author{
P. NOVÁK ${ }^{1}$, G. ZACHAŘOVÁ ${ }^{1}$, T. SOUKUP ${ }^{1}$ \\ ${ }^{1}$ Institute of Physiology, Academy of Sciences of the Czech Republic, Prague, Czech Republic
}

Received June 4, 2009

Accepted January 15, 2010

On-line April 20, 2010

\section{Summary}

We analyzed fiber type composition of soleus and extensor digitorum longus (EDL) muscles of 3- to 19-month-old male and female inbred Lewis rats using histochemical demonstration of mATPase activity. The rats were divided into four groups of the mean age of 3, 6, 9 and 14 months. We found that the soleus muscle of 3-month-old rats contained significantly more of fast $2 \mathrm{~A}$ fibers and less of slow type 1 fibers compared to older rats, while no significant difference was found between female and male rats at any age group. In contrast, we found no significant difference in the EDL fiber type composition among the age groups, but we found that the EDL muscle of female rats contained significantly less $2 \mathrm{~A}$ fibers and more $2 \mathrm{~B}$ fibers than that of male animals. Our results thus revealed an age difference in the soleus muscle and a sex difference in the EDL muscle among postnatal Lewis rats. The number of slow type 1 fibers in the soleus muscle varied between 87 and $100 \%$ and that of $2 \mathrm{~A}$ fibers between 13 and $0 \%$. In the EDL the percentage of type 1 fibers varied between 2.6 and $8.7 \%$, that of $2 \mathrm{~A}$ fibers between 12.6 and $25.8 \%$ and that of $2 B$ fibers between 70.4 and $81.6 \%$. Both muscles thus exhibited a considerable degree of variability among individual animals even in the same age group. Furthermore, a comparison of the Lewis rats with literature data of other rat strains showed that the number of fast $2 \mathrm{~A}$ fibers in the soleus muscle of 4-month-old and older animals decreased in this order: SHR > Lister Hooded > Fisher $344>$ SpragueDawley > Wistar > WBN/Kob > Lewis strain, being almost $20 \%$ in the SHR and less than $2 \%$ in the Lewis rats. In contrast, the "fastest" composition (judged according to the percentage of the fastest $2 \mathrm{~B}$ fibers) of the EDL muscle was demonstrated by Lewis, Wistar and Fisher 344 rats (about $75 \%$ ), while Sprague-Dawley and WBN/Kob rats contained only about $50 \%$ of $2 \mathrm{~B}$ fibers. The percentage of slow type 1 fibers in the EDL was low in all strains (about $5 \%$ ). Our results thus show that the individual, age and sex as well as inter-strain differences in muscle fiber type composition should not be ignored when comparing results of different studies. We also demonstrated that the inbred Lewis strain appears to have more "specialized" muscle composition, as its soleus is the "slowest" and its EDL is the "fastest" among the routinely used rat strains.

\section{Key words}

Rat strains • Rat slow and fast muscles • mATPase and muscle fiber types • Fiber type composition • Inter-strain, individual, age and sex differences

\section{Corresponding author}

T. Soukup, Institute of Physiology, Academy of Sciences of the Czech Republic, Vídeňská 1083, CZ-142 20 Prague, Czech Republic. E-mail: tsoukup@biomed.cas.cz, Fax: +420 24106 2488.

\section{Introduction}

Since Ranvier`s description of red and white muscle fibers in 1873, muscle researchers have used various classifications of fiber types, as this concept has always been important for defining the physiological properties of skeletal muscles. When Bárány (1967) demonstrated that actomyosin ATPase activity can be correlated with the speed of contraction, the histochemical demonstration of myofibrillar ATPase (mATPase) activity (Padykula and Herman 1955) became the most popular 
method of fiber typing, especially after the introduction of acid and alkaline preincubations (Brooke and Kaiser 1970, Guth and Samaha 1970). While the original method allows revealing only slow type I and fast type II fibers, the acid preincubation at $\mathrm{pH} 4.5$ enables the further division of fast fibers into type $2 \mathrm{~A}$ and $2 \mathrm{~B}$ fibers. Thus the fibers that are stained positively after acid preincubations at $\mathrm{pH} 4.3$ and 4.5 of the mATPase reaction are classified as type I fibers, while the fibers that are stained positively after the alkaline preincubation at $\mathrm{pH} 10.3$ and remain unstained after both acid preincubations at $\mathrm{pH} 4.3$ and 4.5 are type $2 \mathrm{~A}$ fibers and the fibers characterized by high mATPase activity after preincubation at $\mathrm{pH} 10.3$ and by moderate staining after preincubation at $\mathrm{pH} 4.5$ are $2 \mathrm{~B}$ fibers. Beside these "pure" fiber types, type $1 \mathrm{C}$ and $2 \mathrm{C}$ fibers, with mixed slow and fast characteristics, stained to a variable extent after both acid and alkaline preincubations have been described (Soukup et al. 1979, Staron and Pette 1993, Talmadge et al. 1999, Smerdu and Soukup 2008, for review see Pette and Staron 1997, 2000, 2001, Stephenson 2006). Although the classification using mATPase reaction was overcome by modern division into four $1,2 \mathrm{~A}, 2 \mathrm{X} / \mathrm{D}$ and $2 \mathrm{~B}$ immunohistochemical fiber types (Soukup 2002, Zachařová et al. 2005, Smerdu and Soukup 2008, Soukup et al. 2009, for review see Hämäläinen and Pette 1993, Schiaffino and Reggiani 1996, Soukup and Jirmanová 2000, Pette and Staron 2000, 2001, Pette 2002, Vadászová et al. 2004, Schiaffino 2010), in the literature, there is a striking number of studies based on the mATPase classification. Despite its limitations, the mATPase reaction offers a quick, cheap and reliable assessment of fiber type composition of mammalian skeletal muscles.

The slow soleus muscle and the fast extensor digitorum longus (EDL) muscle apparently belong to the most frequently analyzed muscles, especially in small laboratory rodents. The soleus, an antigravity muscle located at the rear of the calf, is designed to sustain prolonged activity, while the EDL is a fast muscle involved in short intermittent bursts. The soleus is composed of a great majority of slow type 1 fibers and of a variable, but usually low number of $2 \mathrm{~A}$ fibers. On the other hand, the fast EDL muscle is, according to mATPase, composed of three histochemical muscle fiber types, i.e. of a low number of slow type 1 and of variable proportions of fast 2A and 2B fibers (Soukup et al. 1979, 2009, for review see Pette 2001, 2002).

In the laboratory rat (Rattus norvegicus L.), however, the composition of both muscles can vary among different strains. Previous comparison of 4- to 6-month-old female inbred Lewis rats (Soukup et al. 2002) with several data collected from both sexes of other strains suggested some differences among Lewis, Wistar or Sprague-Dawley rats. Furthermore, the outcome of the fiber type analysis can be affected by differences among individual rats and by the age or sex of the analyzed animals. In our recent paper, we described fiber type composition of the soleus and EDL muscles in 4- to 17month-old female inbred Lewis rats (Soukup et al. 2009), but reliable analysis of male rats is lacking.

The main goal of the present work was to analyze the contribution of individual, age, sex and strain differences to the variability of muscle fiber type composition. We have therefore i) described the composition of 3-6-, 9- and 14-month-old age groups (range 3 to 19 months) of inbred Lewis rats of either sex, ii) compared Lewis female and male rats of the same age, iii) compared individual differences among animals in each experimental group, iv) compared our data on inbred Lewis rats, both males and females, with available literature data of other rat strains of corresponding age and sex.

\section{Materials and Methods}

Animals

Inbred Lewis rats were obtained from the breeding unit of the Institute of Physiology, Academy of Sciences of the Czech Republic, Prague, Czech Republic (Accreditation No. 1020/491/A/00). The maintenance and handling of experimental animals were in accordance with the EU Council Directive (86/609EEC) and the investigation was approved by the Expert Committee of our institute. Soleus and extensor digitorum longus (EDL) muscles were excised from the right and left legs of 19 male and 79 female 3- to 19-month-old rats. The animals were divided into four age groups marked 3, 6, 9 and 14 months with mean age of $3.2 \pm 0.4,6.0 \pm 1.3$, $8.6 \pm 0.4$ and $13.6 \pm 2.7$ months, respectively. They were anesthetized with intraperitoneal injections of $1 \mathrm{ml}$ (100 mg) of Narketan (Ketaminum ut hydrochloridum) per $\mathrm{kg}$ of body weight, followed by $0.5 \mathrm{ml}(10 \mathrm{mg})$ of the myorelaxant Xylapan (Xylazinum ut hydrochloridum) per $\mathrm{kg}$ of body weight and sacrificed by an overdose of the anesthetic.

\section{Myofibrillar adenosine triphosphatase (mATPase)}

Muscle fiber types were determined according to the activity of mATPase (E.C.3.6.1.3) after alkaline 
SOL

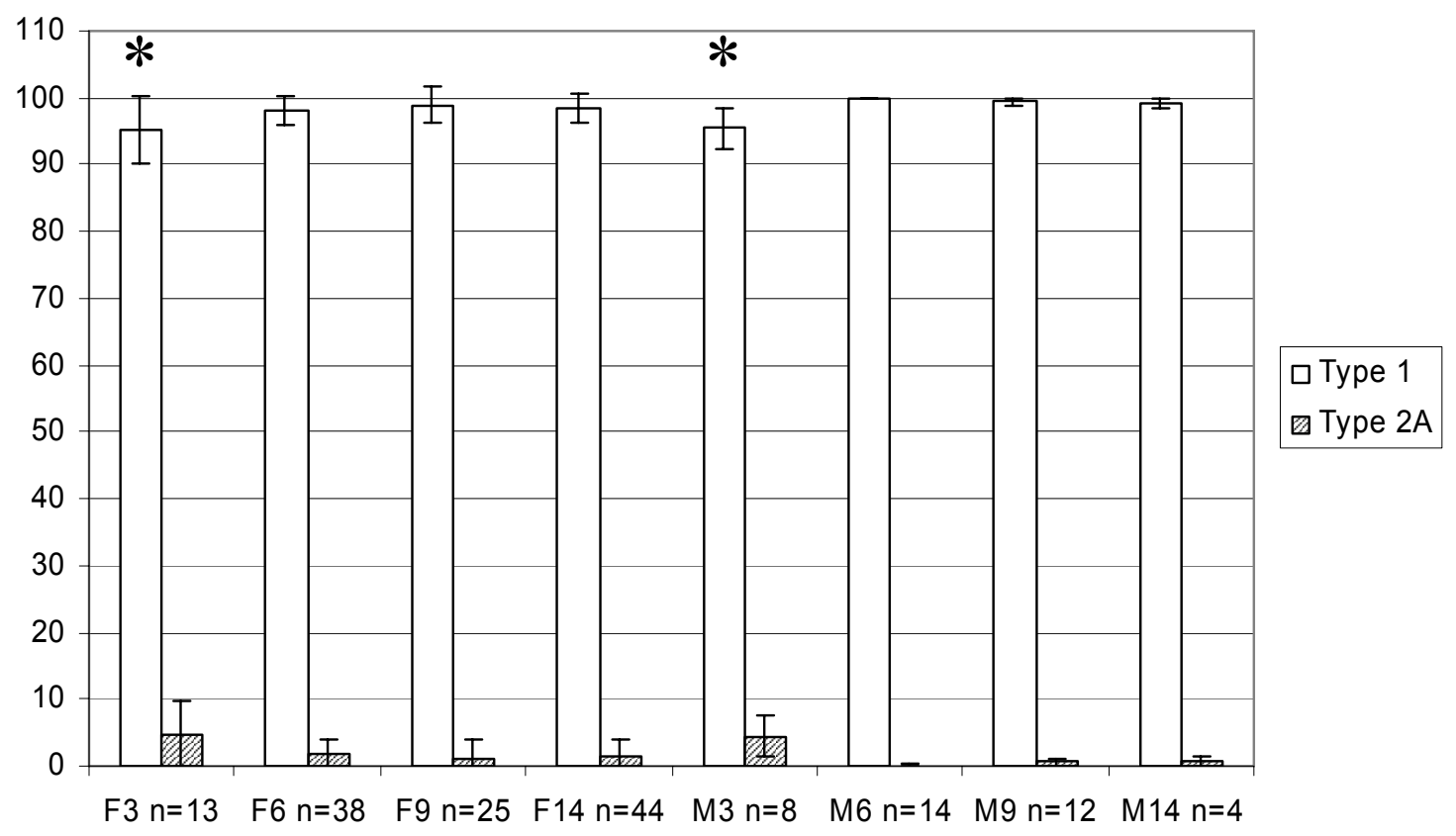

Fig. 1A. Age differences in the fiber type composition of the soleus muscle in female $(F)$ and male $(M)$ postnatal inbred Lewis rats in four age groups. Numerals on the $x$ axis indicate age in months, $n$ indicates the number of muscles analyzed. Asterisks indicate that both female and male 3-month-old rats exhibit a significantly $(p<0.05)$ lower percentage of type 1 fibers when compared with the older animals. There is no significant difference in fiber type composition among 6-, 9- and 14-month-old groups of both female and male rats.

\section{SOL}

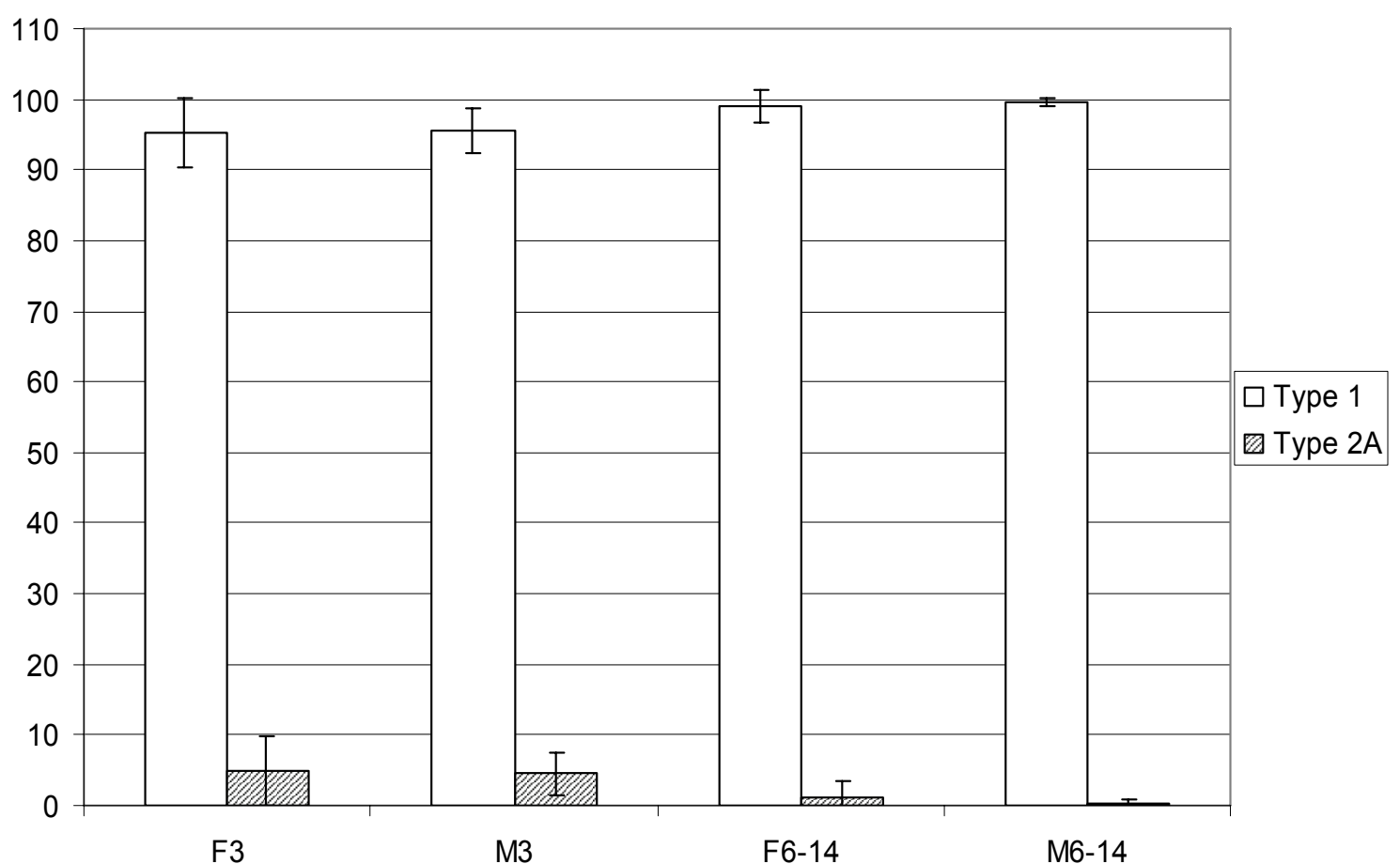

Fig. 1B. Sex differences in the fiber type composition of the soleus muscle between female $(F)$ and male (M) inbred Lewis rats. Numerals on the $x$ axis indicate age in months, the number of analyzed muscles is the same as in Fig. 1A. Note that there are no significant differences between female and male animals of either 3-month-old or 6- to 14-month-old groups. 
( $\mathrm{pH}$ 10.3) and acid ( $\mathrm{pH} 4.5$ and 4.3) preincubations (Brooke and Kaiser 1970, Guth and Samaha 1970). Briefly, excised muscles were frozen in liquid nitrogen and cut on a Leica 3000 cryocut. Two to four $10 \mu \mathrm{m}$ thick serial sections from the center of the muscle were collected on three glasses used for the mATPase reaction. These were followed by 10 glasses with two sections used for immunodetection of muscle fiber types using specific monoclonal antibodies against MyHC isoforms (Soukup et al. 2002, 2009, Smerdu and Soukup 2008). This procedure was repeated three times. The adjacent parts were used for real time detection of MyHC transcripts (Žurmanová et al. 2007, 2008a,b) and SDSPAGE demonstration of MyHC isoforms (Soukup et al. 2002, 2009, Vadászová et al. 2006a,b, VadászováSoukup and Soukup 2007, Přenosil et al. 2008, Smerdu and Soukup 2008).

\section{Quantitative morphological analysis}

The numerical $(\mathrm{N})$ proportions $(\%)$ of muscle fiber types, determined according to the mATPase reaction (serial sections preincubated at $\mathrm{pH} 10.3,4.5$ and 4.3), were assessed by 2-D stereological methods using the principles of an unbiased counting frame (Zachařová and Kubínová 1995). The stereological measurements were performed by the C.A.S.T. Grid System (Olympus, Albertslund, Denmark). In order to achieve realistic estimate of measured parameters, the particular arrangement of the stereological system (size of the counting frame, scanning interval) were chosen according to muscle section size and fiber composition, on the basis of efficacy analysis described in our previous papers (Zachařová and Kubínová 1995, Zachařová et al. 1997, 1999, 2005). The data were expressed as means \pm SD, the differences were evaluated by SigmaStat program (Systat software, Germany) using the one-way analysis of variance (ANOVA) and the t-test and/or Mann-Whitney test.

\section{Results}

\section{Fiber type composition and individual variability}

By the stereological method we analyzed all muscle fibers in the cross sections through the muscle mid-belly (up to 2700 in the soleus and up to 4000 fibers in the EDL muscles).

In total, we have evaluated 160 soleus muscles, 124 from female and 36 from male rats, and the great majority of the fibers were classified as type 1 (including
1C) fibers, the rest were 2A (including 2C) (Fig. 1, Table 1). The analyzed soleus muscles i) were composed exclusively of pure type 1 fibers exhibiting high acidstable and low alkali-stable mATPase activity (12.2\%), ii) contained practically $100 \%$ of type 1 fibers and from these, just few (1-10) fibers exhibited high dual mATPase activity thus corresponding to $1 \mathrm{C}$ fibers (35.1\%), iii) contained a great majority of type 1 fibers (95$99.9 \%$ ) supplemented by a small number of $2 \mathrm{~A}$ (2C) fibers $(36.6 \%)$ or iv) contained a majority of type 1 fibers, but more than $5.5 \%$ (up to $12.7 \%$ ) of type $2 \mathrm{~A}$ (2C) fibers $(16.1 \%)$. The content of type 1 fibers thus varied between 87.3 to $100 \%$ and that of $2 \mathrm{~A}$ fibers varied from zero to $12.7 \%$, which demonstrates a considerable individual variability of the soleus muscle in the inbred Lewis rats.

We have analyzed 129 EDL muscles, 94 from female and 35 from male rats. All EDL muscles contained type $1,2 \mathrm{~A}$ and $2 \mathrm{~B}$ fibers as determined on the basis of mATPase activity after acid preincubation at $\mathrm{pH} 4.5$. The average number of $2 \mathrm{~B}$ fibers in all examined EDL muscles greatly outnumbered $2 \mathrm{~A}$ fibers and the number of type 1 fibers was invariably the lowest (Fig. 2, Table 2). This fiber type composition was characteristic for all EDL muscles, although a certain degree of variability occurred as well. Each fiber type contributed to the individual variability to the similar extent, but the proportions of $2 \mathrm{~A}$ and $2 \mathrm{~B}$ fibers varied most frequently.

We have not specifically searched for hybrid fibers (1C and 2C with the positive staining after both acid and alkali preincubations), as the stereological method does not compare individual fibers in more reactions. Analyses of fibers with acid-stable (type 1) and alkali-stable (2A, 2B) mATPase activity on serial sections showed that the average percentage of hybrid fibers with the positivity in both reactions was low both in the soleus and EDL muscles $(0.6 \pm 1.5 \%$, range 0.0 to $3.2 \%$ ).

\section{Age differences in fiber type composition}

We have analyzed a fiber type composition of the soleus and EDL muscles in four age groups, marked 3-, 6-, 9- and 14-month-old rats. Comparison of the 3-month-old group with older groups revealed a significant difference in the type 1 and 2A composition of the soleus muscle in both sexes (Fig. 1A), but in the EDL muscle $2 \mathrm{~A}$ and $2 \mathrm{~B}$ proportion differed only in female rats (Fig. 2A). In the youngest group we found that about $70 \%$ of soleus muscles contained a variable percentage 
of 2A fibers, but no muscle was composed purely of type 1 fibers. On the other hand, in older age groups almost $80 \%$ of the analyzed soleus muscles in females and more than $90 \%$ in males were solely composed of type 1 (1C) fibers. When we compared 6-, 9- and 14month-old rats, we found no significant difference in fiber type composition either in the soleus (Fig. 1A) or EDL muscles, although 9-month-old females showed a higher percentage of type $2 \mathrm{~A}$ and a lower percentage of 2B fibers compared to 6- and 14-month-old females in the EDL muscle (these differences were of borderline significance) (Fig. 2A).

Table 1. A comparison of our data on female and male Lewis inbred strain rats with literature data on the fiber type composition of the soleus muscle of other rat strains. The fiber type composition was determined on the basis of mATPase activity and is expressed as percentages of type 1 (including $1 \mathrm{C}$ ) and type $2 \mathrm{~A}$ (including $2 \mathrm{C}$ ) fibers.

\begin{tabular}{lll} 
Fiber Types & Type 1 (1C) & Type 2A (2C) \\
\hline
\end{tabular}

\section{LEWIS RATS}

Females, 3-4 months

Present study

$95.2 \pm 4.9$

$4.8 \pm 4.9$

Males, 3-4 months

Present study

$95.5 \pm 3.1$

$4.5 \pm 3.1$

ALL LEWIS RATS, 3-4 months

95.3

4.7

Females, 4-7 months

Soukup et al. (2002)

$96.1 \pm 2.9$

$3.9 \pm 2.9$

Soukup et al. (2009) (4.8 \pm 0.9 months)

$98.4 \pm 2.6$

$1.6 \pm 2.6$

Zachařová et al. (2005)

$98.8 \pm 2.2$

$1.2 \pm 2.2$

Present study

$98.2 \pm 2.2$

$1.8 \pm 2.2$

All females, 4-7 months

97.9

2.1

Females, 7-9 months

Soukup et al. (2009) (7.4 \pm 0.8 months)

$97.3 \pm 3.0$

$2.7 \pm 3.0$

Present study

All females, 7-9 months

$98.9 \pm 2.7$

$1.1 \pm 2.7$

Females, 9-19 months

Soukup et al. (2009) (14.1 \pm 2.3 months)

98.1

1.9

Present study

$97.8 \pm 2.7$

$2.2 \pm 2.7$

All females, 9-19 $\mathrm{m}$

$98.4 \pm 2.2$

$1.6 \pm 2.2$

Lewis females, 4-19 months

98.1

1.9

98.0

2.0

Males, 4-7 months

Present study

$99.9 \pm 0.1$

$0.1 \pm 0.1$

Males, 7-9 months

Present study

$99.4 \pm 0.5$

$0.6 \pm 0.5$

Males, 9-19 months

Present study

$99.3 \pm 0.7$

$0.7 \pm 0.7$

All males, 4-19 months

99.5

0.5

ALL LEWIS RATS, 4-19 months

98.4

1.6

\section{WISTAR RATS}

Females, 3-4 months

Simard et al. (1987) 


\begin{tabular}{|c|c|c|c|c|}
\hline Herbison et al. (1973) & \multicolumn{2}{|l|}{$82.1 \pm 4.0$} & \multicolumn{2}{|l|}{$17.8 \pm 4.0$} \\
\hline Jaweed et al. (1975) & \multicolumn{2}{|l|}{$75.9 \pm 1.2$} & \multicolumn{2}{|l|}{$24.1 \pm 1.2$} \\
\hline Desplanches et al. (1987) & \multicolumn{2}{|l|}{$85.2 \pm 2.4$} & \multicolumn{2}{|l|}{$\sim 14.8$} \\
\hline All females, 3-4 months & \multicolumn{2}{|l|}{80.8} & \multicolumn{2}{|l|}{19.2} \\
\hline \multicolumn{5}{|l|}{ Males, 3-4 months } \\
\hline Yamaguchi et al. (1996) & \multicolumn{2}{|l|}{$85.6 \pm 7.3$} & $8.7 \pm 5.7$ & $(5.7 \pm 4.2)$ \\
\hline Canon et al. (1995) & $85 \pm 2.4$ & $(4.2 \pm 0.7)$ & \multicolumn{2}{|l|}{$10.8 \pm 1.8$} \\
\hline Bigard et al. (1994) & \multicolumn{2}{|l|}{$\sim 91$} & \multicolumn{2}{|l|}{$\sim 9$} \\
\hline Lewis et al. $(1994)^{2)}$ & \multicolumn{2}{|l|}{93.1} & \multicolumn{2}{|l|}{6.9} \\
\hline Sakuma et al. (1995) & \multicolumn{2}{|l|}{$\sim 87$} & \multicolumn{2}{|l|}{$\sim 13$} \\
\hline Oishi et al. (1996) & \multicolumn{2}{|l|}{$88.2 \pm 5.9$} & \multicolumn{2}{|l|}{$\sim 11.8$} \\
\hline Nakano et al. (1995) & \multicolumn{2}{|l|}{$91.7 \pm 6.1$} & \multicolumn{2}{|l|}{8.3} \\
\hline Narusawa (1985) & \multicolumn{2}{|l|}{$\sim 92.3$} & \multicolumn{2}{|l|}{$7.7 \pm 1.4$} \\
\hline All males, 3-4 months & 89.8 & & 10.2 & \\
\hline Other Wistar, 3-4 months & & & & \\
\hline Miyabara et al. (2005), n. d. & $91.5 \pm 6.7$ & $(1.4 \pm 2.6)$ & $7.2 \pm 5.6$ & \\
\hline Soukup et al. (1979), females and males & 73.6 & (4.7) & 21.7 & \\
\hline WISTAR RATS, 3-4 months & 85.6 & & 14.4 & \\
\hline Females, adult & & & & \\
\hline Herbison et al. (1984) & $81 \pm 5$ & & $19 \pm 5$ & \\
\hline Aboudrar et al. (1993) & $85.5 \pm 2.8$ & $(7.8 \pm 2.0)$ & $6.7 \pm 1.1$ & \\
\hline Larsson and Yu (1997) & $95 \pm 5$ & $(1 \pm 1)$ & $3 \pm 4$ & $(1 \pm 1)$ \\
\hline Hall-Cragss et al. (1983) & $89.6(3.3)$ & & $\sim 7.1$ & \\
\hline Larsson and Yu (1997) & $98 \pm 4$ & $(1 \pm 1)$ & $0 \pm 1$ & $(1 \pm 2)$ \\
\hline Simard et al. (1987) & $87.0 \pm 11.7$ & & $13.0 \pm 11.7$ & \\
\hline All females, adult & 91.5 & & 8.5 & \\
\hline Males, adult & & & & \\
\hline Zachařová et al. $(1997)^{1)}$ & $91.6 \pm 2(\mathrm{R}$ & ), $90.4 \pm 3(\mathrm{~L})$ & $8.4 \pm 2(\mathrm{R})$ & $9.6 \pm 3(\mathrm{~L})$ \\
\hline Kovanen and Suominen (1987) & $\sim 89.5 \pm 7$ & & $\sim 10.5$ & \\
\hline Ansved (1995) & $92 \pm 6$ & $(1 \pm 1)$ & $5 \pm 5$ & $(2 \pm 2)$ \\
\hline Larsson and Yu (1997) & $92 \pm 6$ & $(2 \pm 2)$ & $4 \pm 1$ & $(2 \pm 2)$ \\
\hline Joumaa and Léoty (2002) & $80.1 \pm 3.1$ & & $19.9 \pm 3.9$ & \\
\hline Punkt et al. (1999) & 80 & & 15 & $(52 \mathrm{~B})$ \\
\hline Midrio et al. (1992) & 84.5 & & 8.4 & $(7.0)$ \\
\hline Chamberlain and Lewis (1989) & 93.3 & & 6.7 & \\
\hline Ansved (1995) & $97 \pm 4$ & $(1 \pm 1)$ & $2 \pm 3$ & \\
\hline Atrakchi et al. (1994) (WKY) $)^{2)}$ & 75 & & 25 & \\
\hline Li et al. (1996) & $88.6 \pm 5.8$ & $(3.4 \pm 1.6)$ & $5.5 \pm 7.3$ & $(2.4 \pm 1.0)$ \\
\hline Larsson et al. (1994) & $92.3 \pm 6.3$ & $(1.6 \pm 1.8)$ & $3.9 \pm 4.5$ & $(2.3 \pm 2.8)$ \\
\hline Ansved (1995) & $99 \pm 1$ & & $1 \pm 1(2 \mathrm{C})$ & \\
\hline Li et al. (1996) & $99.1 \pm 1.1$ & $(0.3 \pm 0.4)$ & $0.1 \pm 0.2$ & $(0.4 \pm 0.4)$ \\
\hline Larsson et al. (1994) & $96.3 \pm 5.7$ & $(0.5 \pm 0.5)$ & $1.2 \pm 2.4$ & $(1.8 \pm 3.1)$ \\
\hline Kovanen and Suominen (1987) & $\sim 94 \pm 5$ & & $\sim 6$ & \\
\hline Kovanen and Suominen (1987) & $\sim 95 \pm 5$ & & $\sim 5$ & \\
\hline Larsson and Yu (1997) & $96 \pm 6$ & $(1 \pm 1)$ & $1 \pm 2$ & $(2 \pm 3)$ \\
\hline Thomas and Ranatunga (1993) & $77 \pm 4$ & & $20 \pm 4$ & $(3 \pm 1)$ \\
\hline Lieber et al. (1986) (inbred isogeneic) & $91.3 \pm 0.9$ & & $8.7 \pm 0.9$ & \\
\hline
\end{tabular}




All males, adult 90.

Wistar females and males, adult

Soukup et al. (1979)

WISTAR RATS, adult

SPRAGUE-DAWLEY RATS

Females, 3-4 months

Martin and Romond (1975)

Caiozzo et al. (1997)

Staron et al. (1998)

All females, 3-4 months

Males, 3-4 months

Itoh et al. (1992)

Eisen et al. (1975)

Martin and Romond (1975)

Tian and Feng (1990)

All males, 3-4 months

SPRAGUE-DAWLEY RATS, 3-4 months

Females, adult

Luginbuhl et al. (1984)

Males, adult

Pousson et al. (1991)

Almeida-Silveira et al. (1994)

Ho et al. (1983)

Ianuzzo et al.(1977)

Ianuzzo et al. (1980)

Vesely et al. (1999)

Armstrong and Phelps (1984)

All males, adult

Sprague-Dawley rats, adult

Gillespie et al. (1987), females and males

Ariano et al. (1973), n. d.

Lieber et al. (1986), n. d.

SPRAGUE-DAWLEY RATS, adult

\section{FISHER 344 RATS}

Staron et al. (1998)

Staron et al. (1999)

FISHER 344 MALES, 3-4 months

\section{LISTER HOODED RATS}

Females, 3-4 months

Rajinkin (1984)

Rajinkin (1984)

All females, 3-4 months
90.7

9.3

86.2

13.8

90.7

9.3

\begin{tabular}{|c|c|c|}
\hline $84.3 \pm 3.6$ & & $15.7 \pm 3.6$ \\
\hline$\sim 80$ & & $\sim 20$ \\
\hline $87.4 \pm 5.7$ & $(1.9 \pm 2.0)$ & $5.9 \pm 2.8$ \\
\hline 84.5 & & 15.5 \\
\hline $80.8 \pm 2.5$ & & $19.2 \pm 2.2$ \\
\hline $79.0 \pm 1.8$ & & $21.0 \pm 1.8$ \\
\hline $83.5 \pm 1.1$ & & $16.5 \pm 1.1$ \\
\hline $90.3 \pm 5.9$ & & $9.7 \pm 5.9$ \\
\hline 83.4 & & 16.6 \\
\hline
\end{tabular}

$83.9-16.1$

$84.8 \pm 3.6$

$1.6 \pm 0.9$

$(13.6 \pm 2.2)$

$82.8 \pm 3.1$

$17.2 \pm 2.8$

$85.6 \pm 5.8 \quad(0.6 \pm 0.3)$

$13.8 \pm 5.6$

83

$84.0 \pm 1.4$

17

83.7

$16.0 \pm 1.4$

16.3

$94 \pm 3.7$

$87 \pm 4$

$5 \pm 1.6$

$13 \pm 4$

85.8

14.2

80

20

84

94.5

16

5.5

85.8

14.2

$(4.8 \pm 4.8)$

$(4.8 \pm 4.8)$ 


\begin{tabular}{lll}
\hline Males, 3-4 months & & \\
Rajinkin (1984) & $\sim 77$ & $\sim 23 \pm 3$ \\
Rajinkin (1984)) & $\sim 84.5$ & $\sim 15.5 \pm 3$ \\
All males, 3-4 months & $\mathbf{8 0 . 8}$ & $\mathbf{1 9 . 3}$ \\
LISTER HOODED RATS, 3-4 months & $\mathbf{8 2 . 9}$ & $\mathbf{1 7 . 1}$ \\
& & \\
Females, adult & & \\
Rajinkin (1984) & $\sim 83$ & \\
Males, adult & & \\
Rajinkin (1984) & $\sim 80$ & $\sim 20 \pm 5$ \\
LISTER HOODED RATS, adult & $\mathbf{8 1 . 5}$ & $\mathbf{1 8 . 5}$
\end{tabular}

\section{SPONTANEOUSLY HYPERTENSIVE RATS (SHR)}

Males, 3-4 months

Lewis et al. (1994)

$\begin{array}{ll}81.5 \pm 1.5 & 18.5 \pm 1.5\end{array}$

Males, adult

Atrakchi et al. (1994)

$81 \quad 19$

SHR MALES, adult

81

19

\section{WBN/Kob RATS}

WBN/Kob non-diabetic females, 10-24 months

$\begin{array}{lcc}\text { Ozaki } \text { et al. }(2001)^{3)} & 96.9 & 3.1 \\ \text { Ozaki } \text { et al. }(2001)^{3)} & 97.0 & 3.0 \\ \text { All females } & \mathbf{9 7 . 0} & 3.1 \\ \text { WBN/Kob diabetic males, } 10-24 \text { months } & & \\ \text { Ozaki } \text { et al. }(2001)^{3)} & 95.3 & 4.7 \\ \text { Ozaki } \text { et al. }(2001)^{3)} & 98.9 & 1.1 \\ \text { All males } & \mathbf{9 7 . 1} & \mathbf{2 . 9} \\ \text { WBN/Kob RATS, adult } & \mathbf{9 7 . 0} & \mathbf{3 . 0}\end{array}$

${ }^{1)}$ Right (R) and left $(L)$ limb, respectively; ${ }^{2)}$ Wistar-Kyoto rats, no differences compared to normal Wistar rats were found; ${ }^{3)}$ Classified as $2 C$ fibers (with no type 1 fibers). Data are mean $\pm S D$, n. d. - sex not determined.

Sex differences in fiber type composition

We did not find any significant difference in the content of type 1 and $2 \mathrm{~A}$ fibers between male and female soleus muscles in any age group (Figs 1A,B). On the other hand, we found that the EDL muscles of the female rats contained significantly less $2 \mathrm{~A}$ and more $2 \mathrm{~B}$ fibers compared to the male rats, while there were no significant differences in the type 1 fiber proportion (Fig. 2B). Comparison of fiber type composition of 3-month-old and older groups of male and female rats revealed different results in soleus and EDL muscles. While a significant difference in the content of type 1 and $2 \mathrm{~A}$ fibers between the 3-month-old and older groups occurred both in male and female soleus muscles (Fig. 1A), the EDL muscles of the 3-moth-old rats contained significantly less $2 \mathrm{~A}$ and more $2 \mathrm{~B}$ fibers compared to the older groups only in females, while no such tendency was observed in male rats (Figs 2A, B).

\section{Strain differences in fiber type composition}

Our data demonstrate that the soleus muscle of Lewis rats contains the highest percentage of type 1 fibers, comparable with literature data on WBN/Kob rats, but higher than the values found in Wistar and SpragueDawley, Fisher 344, Lister Hooded and SHR rats (Fig. 3, upper panel; Table 1). The EDL muscles in all examined strains contained a low number of type 1 fibers, varying between the lowest percentage in the Sprague-Dawley and the highest in the WBN/Kob rats (Fig. 3, lower panel; Table 2). On the other hand, the highest percentage of the 
EDL

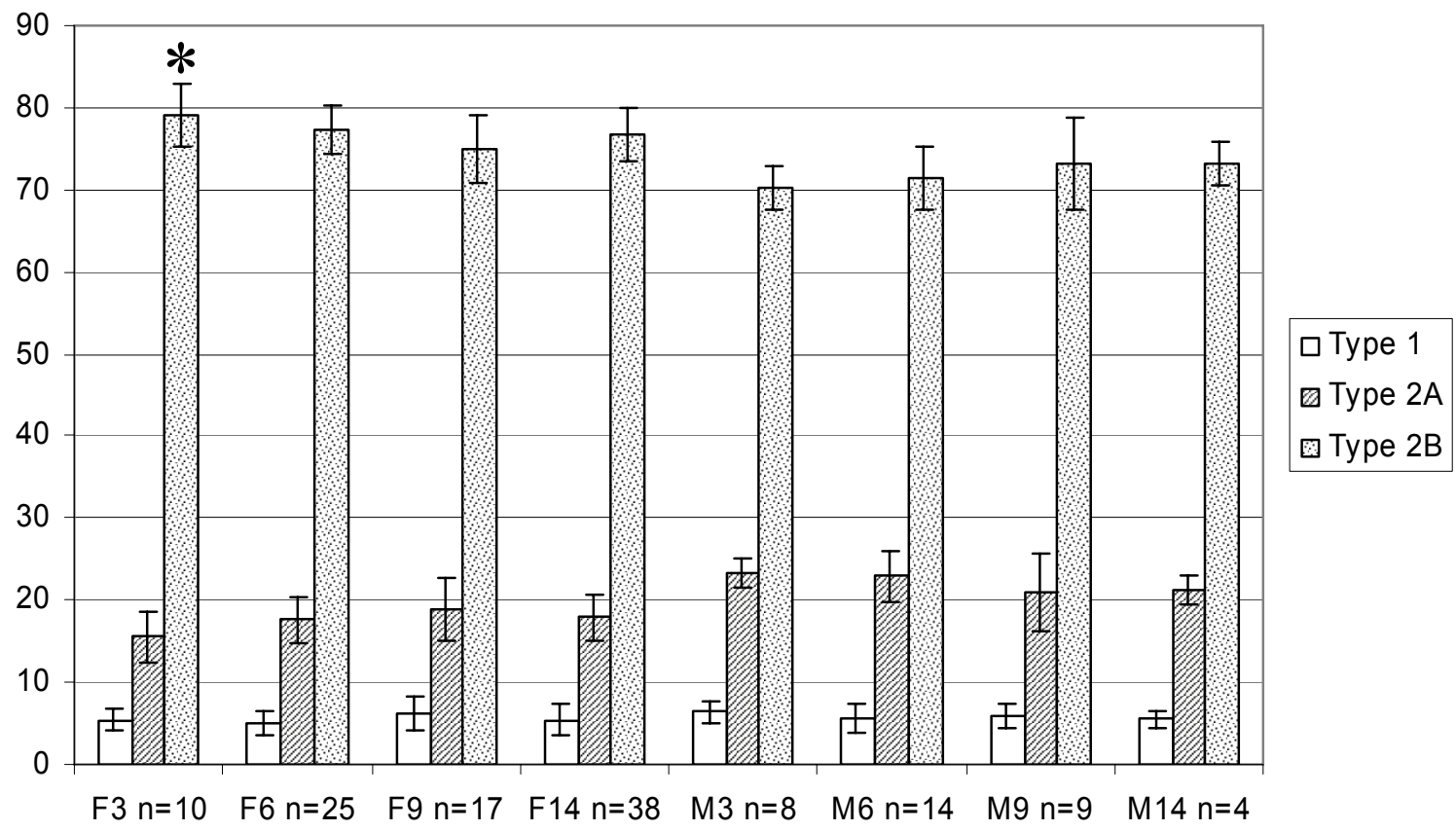

Fig. 2A. Age differences in the fiber type composition of the extensor digitorum longus (EDL) muscle in female (F) and male (M) postnatal inbred Lewis rats in four age groups. Numerals on the $x$ axis indicate age in months, $n$ indicates the number of muscles analyzed. Asterisk indicates that 3-month-old females, but not males, exhibit a significantly $(p<0.05)$ lower percentage of $2 \mathrm{~A}$ and a higher percentage of $2 \mathrm{~B}$ fibers when compared with the sum of older female rats. There is no significant difference in type 1 fibers among any age groups of either sex.

\section{EDL}

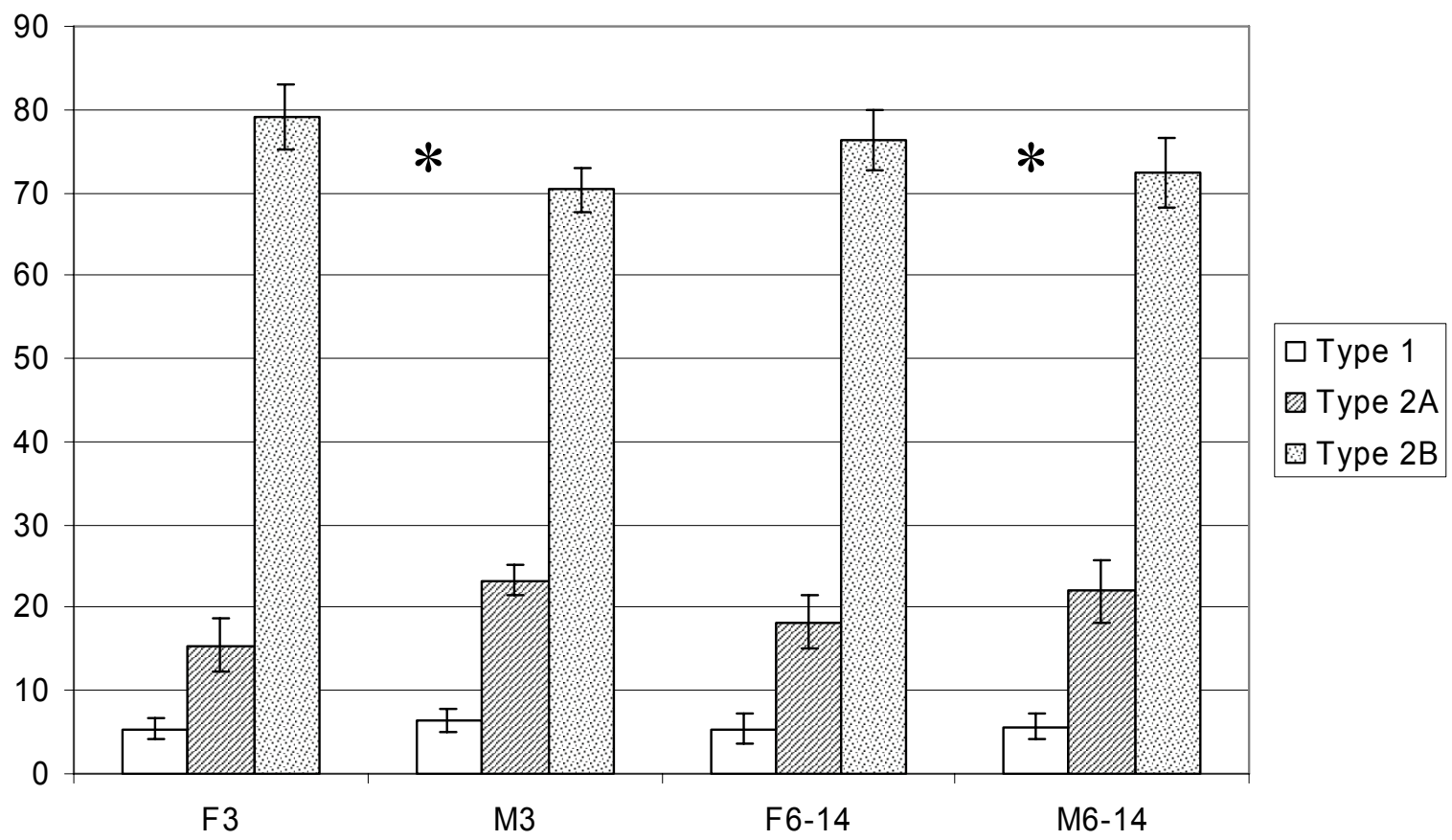

Fig. 2B. Sex differences in the fiber type composition of the extensor digitorum longus (EDL) muscle between female (F) and male (M) inbred Lewis rats. Numerals on the $x$ axis indicate age in months, the number of analyzed muscles is the same as in Fig. 2A. Asterisks indicate that there are significant $(p<0.05)$ differences in the contents of $2 A$ and $2 B$ fibers between female and male rats in both the 3-month-old and 6- to 14-month-old groups. The differences in the percentages of type 1 fibers are not significant. 
fastest 2B fibers was exhibited by the Lewis and Wistar rats (about $75 \%$ ) and slightly lower by the Fisher 344 rats, while the Sprague-Dawley and $\mathrm{WBN} / \mathrm{Kob}$ rats contained about $50 \%$ of 2B fibers (Fig. 3, lower panel; Table 2).

\section{Discussion}

Our results on the inbred Lewis rats confirmed that i) the fiber type composition does not change after the 4th month of age, ii) the soleus of 3-month-old rats, however, contains significantly less type 1 fibers and more $2 \mathrm{~A}$ fibers compared to older animals, iii) there is a sex difference in the proportion of $2 \mathrm{~A}$ and $2 \mathrm{~B}$ fiber types in the EDL muscle and iv) the fiber type composition of inbred Lewis rats differs from literature data of other routinely used rat strains.

\section{Justification of mATPase reaction for fiber typing}

As the great majority of studies analyzing fiber type composition, especially of the older ones, is based on the determination of mATPase activity, only our data dealing with this reaction were suitable for the comparison. Furthermore, in our previous study (Soukup et al. 2009) there was no significant difference in the percentages of type 1 and type $2 \mathrm{~A}$ fibers in the soleus and EDL muscles based on mATPase reaction compared to immunocytochemical determination using specific monoclonal antibodies against type 1 and $2 \mathrm{~A}$ fibers. The undisputable advantage of immunoreactions enabling separate recognition of $2 \mathrm{X} / \mathrm{D}$ fibers does not bring any gain when comparing with literature data based on the division into three fiber types $(1,2 \mathrm{~A}$ and $2 \mathrm{~B})$.

\section{Fiber type composition and individual variability}

Our present results for Lewis rats correspond very well with our previously published data (Soukup et al. 2002, 2009, Zachařová et al. 2005). In the soleus muscle, the percentage of $2 \mathrm{~A}$ fibers varied between zero and $13 \%$, although some fibers, determined as $2 \mathrm{~A}$ fibers, apparently bore a resemblance to hybrid $2 \mathrm{C}$ fibers. It is well-known that the soleus hybrid fibers exhibit physiological characteristics between slow type 1 and fast 2A fibers (for review see Pette and Staron 2001, Stephenson 2006). Although 2A fibers are capable of faster contraction, they are similarly as type 1 fibers fatigue resistant, capable to cover their metabolic requirements by the aerobic energy pathway. It can be thus hardly expected that most of the observed individual variability will have any marked effect on physiological functions of the soleus muscles. On the other hand, the EDL is a fast muscle composed in all rat strains of a low percentage of slow type 1 fibers, a medium number of fast $2 \mathrm{~A}$ and a majority of the fastest $2 \mathrm{~B}$ fibers. Although individual EDL muscles in Lewis rats exhibit different proportions of $2 \mathrm{~A}$ and $2 \mathrm{~B}$ fibers compared to mean composition, these differences (similarly as in the soleus muscles) do not suggest that they will have a significant impact on EDL muscle performance. The existence of marked fiber type differences among individual rats was already recognized previously (Hall-Craggs et al. 1983, Li et al. 1996, Soukup et al. 2009) and it can, however, significantly affect the fiber type percentage in studies analyzing only a low number of animals.

Our data on the Lewis rats are very reliable as they are based on the stereological evaluation of all fibers in the muscle, which is not the case in many other studies. An estimate of fiber type composition from a limited muscle sample can affect results especially in the EDL muscle, which shows considerable variation between white and red portions (Niederle and Mayr 1978). The former is composed from $2 \mathrm{~B}$ and $2 \mathrm{~A}$ fibers, while the latter predominantly from $2 \mathrm{~A}$ fibers supplemented by type 1 fibers. It means that the analysis of the red portion would thus increase the percentage of $2 \mathrm{~A}$ against $2 \mathrm{~B}$ fibers.

\section{Age differences in fiber type composition}

There are many studies analyzing development of the soleus muscle and less of the EDL muscle during the early postnatal period, but only few of them describe fiber type composition within a longer period (Ho et al. 1983, Rajikin 1984, Narusawa 1985, Kovanen and Suominen 1987, Simard et al. 1987, Li et al. 1996, Wigston and English 1992, Larsson and Yu 1997). Those analyzing the soleus all describe significant increase of slow type 1 and decrease of type 2A fibers during the first two postnatal months followed by minor changes during the 3rd and 4th months of age. Our results showed that the soleus muscle of both male and female Lewis rats in the 3-month-old group still contained a lower percentage of type 1 fibers compared to older rats. The literature data on Wistar rats (Table 1) point to a similar difference in female, but not in male Wistar rats, while the data on Sprague-Dawley rats show very minor differences. Furthermore, Larsson et al. (1994) and Larsson and Yu (1997) reported differences between 3- to 7- and 20- to 25-month-old Wistar rats that contained about 92 and 
$96 \%$ of type 1 fibers, respectively. We found a similar difference, when we selected 3- to 7- and 14- to 19month-old female Lewis rats from our large sample, but this difference was not significant. Larsson et al. (1994) and Larsson and $\mathrm{Yu}$ (1997) reported an increase of 2A fibers on the expense of type 1 and $2 \mathrm{~B}$ fibers in the EDL muscle of very old Wistar rats (aged 20-25 months) compared to 3- to 7-month-old ones. We have found a similar shift of $2 \mathrm{~A}$ and $2 \mathrm{~B}$ fibers in the EDL muscles between 3- to 7- and 14- to 19-month-old Lewis rats, but, similarly as in the soleus, this difference was not significant. The literature data on age differences of the EDL in other strains are less frequent and do not allow any suggestion. We can thus conclude that after the period of profound changes during the first three postnatal months (Kugelberg 1976, Asmussen and Soukup 1991, for review see Soukup and Jirmanová 2000, Pette and Staron 2001) the final tuning of the physiologically most proper fiber type composition of the rat soleus and EDL muscles is apparently finished by the end of the fourth month and the composition remains relatively stable throughout the whole adulthood.

Furthermore, in a recent review (Schiaffino 2010), it was shown that the age differences of muscle composition between developing and adult muscles can lead to misinterpretation of results dealing with effects of e. g. transcription factors on fiber type composition. For instance the presumed induction of fast-to-slow transformation by calcineurin (Naya et al. 2000) can be rather a block of the slow-to-fast switch (Schiaffino 2010) that occurs after birth in fast muscles. Similarly, the transformation block of fast-to-slow switch in the rat soleus was suggested for the effect of suspension hypokinesia performed in 3- to 4-week-old rats (Asmussen and Soukup 1991), although suspension hypokinesia is generally supposed to induce slow-to-fast transitions (e. g. Desplanches et al. 1987, Canon et al. 1995, Bigard et al. 1994, Caiozzo et al. 1997).

Table 2. A comparison of our data on female and male Lewis inbred strain rats with literature data on the fiber type composition of the EDL muscle of other rat strains. The fiber type composition was determined on the basis of mATPase activity and is expressed as percentages of type 1 , type $2 \mathrm{~A}$ and $2 \mathrm{~B}$ fibers.

\begin{tabular}{llll}
\hline Fiber Types & Type 1 (1C) & Type 2A (2C) & Type 2B \\
\hline
\end{tabular}

\section{LEWIS RATS}

Females, 3-4 months

Present study

$\begin{array}{lll}5.4 \pm 1.3 & 15.5 \pm 3.2 & 79.1 \pm 3.9 \\ 6.4 \pm 1.4 & 23.3 \pm 1.9 & 70.3 \pm 2.6 \\ \mathbf{5 . 9} & \mathbf{1 9 . 4} & \mathbf{7 4 . 7}\end{array}$

LEWIS RATS , 3-4 months

$6.4 \pm 1.4$
$\mathbf{5 . 9}$

Females, 4-7 months

Soukup et al. (2002) (4-6 months)

$5.5 \pm 1.0$

$5.9 \pm 0.7$

Soukup et al. (2009) (4.8 \pm 0.9 months)

$5.0 \pm 1.6$

Zachařová et al. (2005) (7.0 \pm 2.9 months)

All females, 4-7 months

Females, 7-9 months

Soukup et al. (2009) (7.4 \pm 0.8 months)

Present study

All females, 7-9 months

Females, 9-19 months

Soukup et al. (2009) (14.1 \pm 2.3 months)

Present study

All females, 9-19 months

All Lewis females, 4-19 months
$5.8 \pm 1.0$

5.6

$5.4 \pm 2.3$
$6.2 \pm 2.2$
$\mathbf{5 . 8}$

$7.3 \pm 2.5$
$5.4 \pm 1.9$
$\mathbf{6 . 4}$
$\mathbf{5 . 8}$

$18.8 \pm 1.7$

$16.9 \pm 3.7$

$17.6 \pm 2.8$

$17.2 \pm 3.3$

17.6

$75.7 \pm 2.2$

$77.2 \pm 3.9$

$77.3 \pm 3.0$

$77.0 \pm 3.4$

76.8

$76.3 \pm 4.1$

$75.0 \pm 4.2$

75.7

$76.5 \pm 2.5$

$76.7 \pm 3.3$

76.6

76.5 
Males, 4-7 months

Present study

Males, 7-9 months

Present study

Males, 9-19 months

Present study

All Lewis males, 4-19 months

LEWIS RATS, adult (4-19 months)

\section{WISTAR RATS}

Wistar, females and males, 3-4 months Soukup et al. (1979)

$4.5(2.3)$

Males, 3-4 months

Bigard et al. (1994)

WISTAR RATS, 3-4 months

Females, adult

Larsson and Yu (1997) (4-7 months)

Larsson and Yu (1997) (21-25 months)

All females, adult

Males, adult

Larsson et al. (1994) (3-6 months)

Green et al. (1984)

Larsson and Yu (1997) (4-7 months)

Larsson et al. (1994) (20-24 months)

Larsson and $\mathrm{Yu}$ (1997) (21-25 months)

All males, adult

WISTAR RATS, adult

\section{SPRAGUE-DAWLEY RATS}

Males, 3-4 months

Tian and Feng (1990)

$79 \pm 6$

$3 \pm 1$

3.5

$3.4 \pm 1.1$

$7.7,3.1$

$4 \pm 1$

$3.3 \pm 0.8$

$3 \pm 1$

4.1

3.9

$10 \pm 7$

$87 \pm 6$

12.0

83.0

Males, adult

Vesely et al. (1999)

Armstrong and Phelps (1984)

Ariano et al. (1973), n.d.

Egginton (1990), n.d.

SPRAGUE-DAWLEY RATS, adult

\section{WBN/Kob RATS}

Non-diabetic females, 10-24 months

Ozaki et al. (2001)

Ozaki et al. (2001)
$76.1 \pm 4.4$

$70.2,80.7$

$75 \pm 6$

$72 \pm 6.1$

$72 \pm 6$

74.3

18.5

76.5

$\begin{array}{lll}7 \pm 2.0 & 45 \pm 2.4 & 48 \pm 1.8 \\ 2 \pm 1 & 42 \pm 7 & 56 \pm 8 \\ 3 & 59 & 38 \\ 3 & 36.2 & 60.8\end{array}$

3.8

45.6

50.7 


\begin{tabular}{llll}
\hline All females & $\mathbf{8 . 3}$ & $\mathbf{4 9 . 7}$ & $\mathbf{4 2 . 1}$ \\
$\begin{array}{l}\text { Diabetic males, 10-24 months } \\
\text { Ozaki et al. (2001) }\end{array}$ & 8.2 & 50.0 & 41.9 \\
Ozaki et al. (2001) & 7.5 & 39.5 & 53.0 \\
All males & $\mathbf{7 . 9}$ & $\mathbf{4 4 . 8}$ & $\mathbf{4 7 . 5}$ \\
WBN/Kob RATS, adult & $\mathbf{8 . 1}$ & $\mathbf{4 7 . 2}$ & $\mathbf{4 4 . 8}$ \\
FISHER 344 RATS & & & \\
& & & \\
Males, 3-4 months & $4.0 \pm 1.6(0.8 \pm 0.6)$ & $15.5 \pm 2.8$ & $29.9 \pm 4.9$ \\
Staron et al. (1999) & & $(0.6 \pm 0.6)$ & $36.5 \pm 4.6$ (IID) \\
& & $7.3 \pm 3.4$ (IIAD) & $5.4 \pm 2.9$ (IIDB) \\
Males, adult & & & $26.4 \pm 2.7$ \\
Kraemer et al. (2000) & $4.4 \pm 1.4(0.9 \pm 0.7)$ & $16.5 \pm 2.0$ & $36.9 \pm 2.0$ (IID) \\
& & $(0.9 \pm 1.0)$ & $6.3 \pm 1.5$ (IIDB) \\
FISHER 344 RATS, adult & & $7.7 \pm 1.5$ (IIAD) & $\mathbf{6 9 . 6}$ \\
\hline
\end{tabular}

Data are mean $\pm S D, n$. d. - sex not determined.

\section{Sex differences in fiber type composition}

Our data did not reveal any significant sex difference in the composition of the soleus muscle, although adult males contained higher percentages of type 1 (and lower percentages of 2A) fibers than females as more male than female soleus muscles were solely composed of slow type 1 and $1 \mathrm{C}$ fibers. It also appeared that soleus muscles in males achieved their "slow" composition earlier than in female Lewis rats. We speculate that these differences can be correlated with different growth rates of female and male rats as evident already four weeks after birth (http://www.harlan.com/ research_models_and_services). The literature data on adult Wistar, Sprague-Dawley and WBN/Kob rats show no sex difference between female and male soleus muscles, with one exception, i. e. Wistar young females contained less type 1 fibers than the male rats of the same age, which can be again related to faster growth in males (http://www.harlan.com/research_models_and_services) (Table 2). Although the most evident growth differences between females and males are reported for the SpragueDawley rats (http://www.harlan.com/research_ models_ and_services), the collected literature data do not show any difference in the soleus fiber type composition either in young or older animals (Table 1). On the other hand, we found a significant difference in the EDL muscle between female and male inbred Lewis rats, as females contained more of faster $2 \mathrm{~B}$ and less of $2 \mathrm{~A}$ fibers compared to male EDL muscles (Fig. 2B). The latter difference also appeared from the comparison of literature data on Wistar rats (Table 2). No sex difference was detected in the soleus muscle of 2.5-months-old CFHB-Wistar rats (Pullen 1977) and between WBN/Kob non diabetic female and diabetic male rats (Ozaki et al. 2001). On the other hand, a consistently higher proportion of $2 \mathrm{~A}$ fibers was found in the soleus of 4- to 20-week-old Lister Hooded male rats compared to female rats (Rajikin 1984). The same author speculated that this difference (that was the highest at 8 and 12 weeks of age, i.e. in puberty) can be caused by differences in the level of circulating testosterone. The sex differences observed in limb muscles are quite small which is in contrast with the sexually dimorphic muscles, like guinea pig temporalis or rat levator ani muscles (d`Albis et al. 1991).

\section{Strain differences in fiber type composition}

Comparison of fiber type composition of different rat strains demonstrates that the soleus muscle of Lewis rats is the "slowest", as it exhibits the highest percentage of type 1 fibers, followed by WBN/Kob, Wistar and Sprague-Dawley, Fisher 344, Lister Hooded and SHR rats (Table 1, Fig. 3). Furthermore, the inbred 

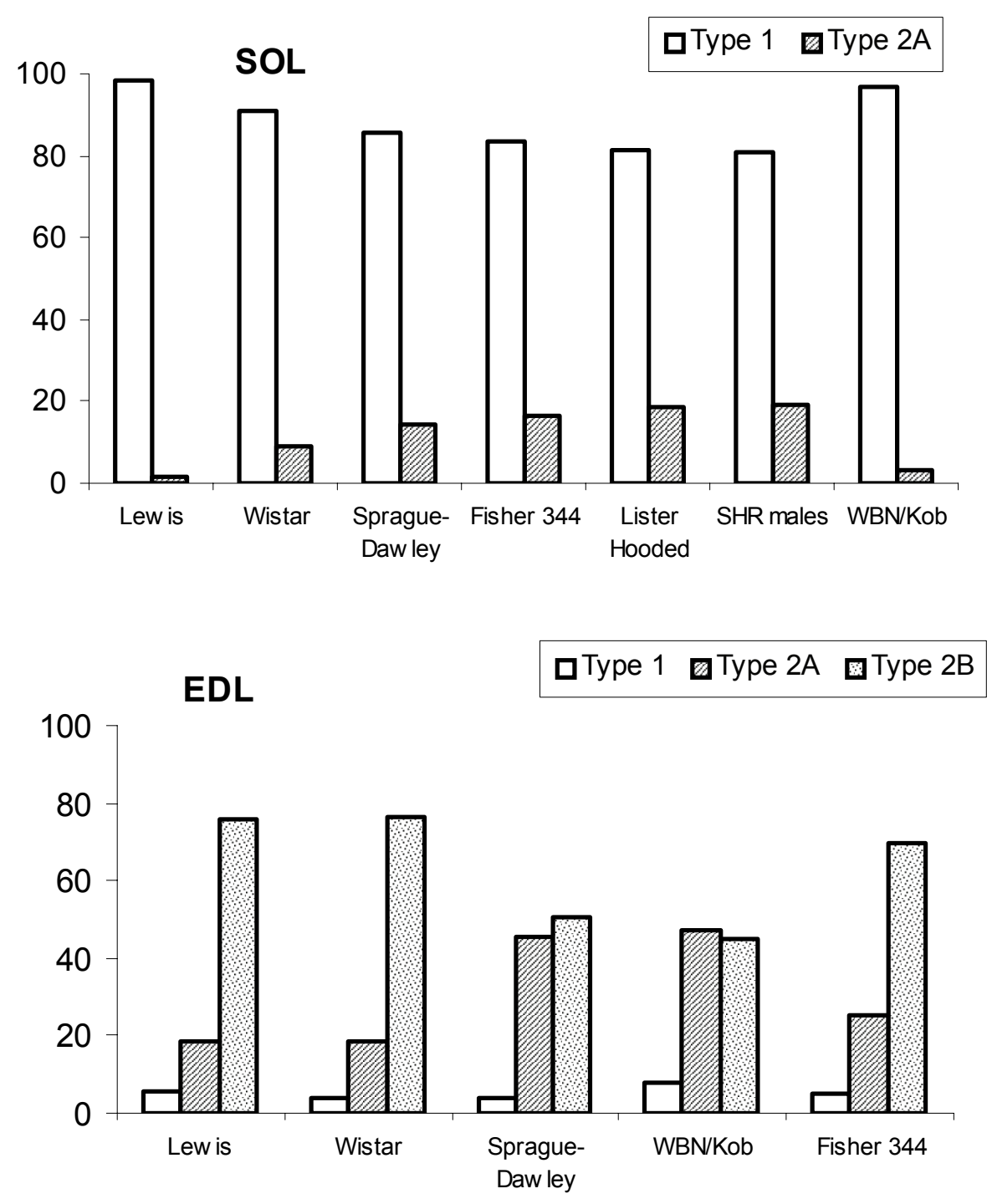

Fig. 3. Mean fiber type composition of the soleus (SOL, upper panel) and extensor digitorum longus (EDL, lower panel) muscles of 4-month-old and older rats as summarized from the literature data on different rat strains (for further details see Tables 1 and 2 ).

Lewis rats attain the very high percentage of type 1 fibers in the soleus muscle earlier than the other strains. It can be related to the higher natural levels of serum thyroxine (http://www.harlan.com/research_models_and_services). This fact was demonstrated experimentally, as hyperthyroid rats achieved adult soleus composition earlier than euthyroid and hypothyroid rats (VadászováSoukup and Soukup 2007). In the EDL muscle, the highest percentage of the fastest 2B fibers (and the lowest of 2A fibers) was exhibited by Lewis, Wistar and Fisher rats, while Sprague-Dawley and WBN/Kob contained an almost equal percentage of $2 \mathrm{~B}$ and $2 \mathrm{~A}$ fibers (Table 2, Fig. 3).

It was shown that the soleus muscle of SHR rats contains a three times greater proportion of fast fibers and its twitch contraction and relaxation time is $12-15 \%$ faster compared to normotensive WKY rats (Lewis et al. 1994). This means that the increase of about $14 \%$ of fast 2A fibers leads to a similar percentage change of physiological parameters. Corresponding or even higher differences in contraction and relaxation time can be expected e. g. between SHR and Lewis rats as the percentage of the type 1 fibers in soleus muscles ranges from about $80 \%$ in the SHR to almost $99 \%$ in the Lewis rats. Similarly, the difference in the content of type $2 \mathrm{~B}$ in the EDL between Sprague-Dawley or WBN/Kob (about $50 \%$ ) and Lewis or Wistar rats (about $75 \%$ ) seems to be high enough to have physiological consequences. Our results show that regarding soleus fiber type composition, Lewis and WBN/Kob rats form a group of "very slow" 
strains, while Sprague-Dawley, Fisher 344, Lister Hooded and SHR rats correspond to the "relatively faster" strains, with Wistar rats in between these two strain groups. Regarding the EDL, however, the Lewis and Wistar rats form the "fast" group, while the SpragueDawley and WBN/Kob rats represent the "relatively slower" strains, the Fisher 344 rats being in between these groups. It seems that the muscle fiber type composition is specific for the given strain regardless of it being inbred or outbred. Although we followed only the soleus and EDL muscles, it can be supposed that similar strain differences are present in other or even in all skeletal muscles. The strain differences thus must not be ignored in comparative studies, when a comparison of physiological results of different strains is made.

\section{Conclusions}

Our results revealed substantial individual variability in muscle fiber type composition both in the soleus and EDL muscles, age differences in the soleus and sex differences in the EDL muscles. A comparison of the Lewis and other rat strains revealed obvious interstrain differences, which demonstrate that for comparative studies, the inter-strain differences must be seriously considered. The results also show that the inbred Lewis rats appear to be the most "specialized" in respect to skeletal muscle composition, as their soleus is the slowest and their EDL is the fastest among compared rat strains.

\section{Conflict of Interest}

There is no conflict of interest.

\section{Acknowledgements}

We are grateful to Ms Kateřina Kopecká and Ms Martina Pytlová for their excellent technical assistance. The study was supported by MYORES LSH-CT-2004-511978, MSMT CR LC554 and GACR 304/08/0256 and $305 / 09 / 1228$ grants and by the Research project AV0Z 50110509 .

\section{References}

ABOUDRAR S, SEMPORE B, KOUBI H, DECHAUD H, DESPLANCHES D: Effects of adrenalectomy or RU-486 on rat muscle fiber during hindlimb suspension. $J$ Appl Physiol 75: 2767-2773, 1993.

ALMEIDA-SILVEIRA MI, PÉROT C, POUSSON M, GOUBEL F: Effects of stretch-shortening cycle training on mechanical properties and fibre type transition in the rat soleus muscle. Pflugers Arch 427: 289-294, 1994.

ANSVED T: Effects of immobilization on the rat soleus muscle in relation to age. Acta Physiol Scand 154: 291-302, 1995.

ARIANO MA, ARMSTRONG RB, EDGERTON VR: Hindlimb muscle fiber populations of five mammals. J Histochem Cytochem 21: 51-55, 1973.

ARMSTRONG RB, PHELPS RO: Muscle fiber type composition of the rat hindlimb. Am J Anat 171: 259-272, 1984.

ASMUSSEN G, SOUKUP T: Arrest of developmental conversion of type II to type I fibers after suspension hypokinesia. Histochem J 23: 312-322, 1991.

ATRAKCHI A, GRAY SD, CARLSEN RC: Development of soleus muscles in SHR: relationship of muscle deficits to rise in blood pressure. Am J Physiol 267: C827-C835, 1994.

BÁRÁNY M: ATPase activity of myosin correlated with speed of muscle shortening. J Gen Physiol 50: 197-218, 1967.

BIGARD AX, LIENHARD F, MERINO D, SERRURIER B, GUEZENNEC CY: Effects of growth hormone on rat skeletal muscle after hindlimb suspension. Eur J Appl Physiol 69: 337-343, 1994.

BROOKE MH, KAISER KK: Muscle fiber types :How many and what kind? Arch Neurol (Chic.) 25: 360-366, 1970.

CAIOZZO VJ, BAKER MJ, MCCUE SA, BALDWIN KM: Single-fiber and whole muscle analyses of MHC isoform plasticity: interaction between T3 and unloading. Am J Physiol 273: C944-C952, 1997.

CANON F, BIGARD AX, MERINO D, LIENHARD F, GUEZENNEC CY: Effects of chronic low frequency stimulation on structural and metabolic properties of hindlimb suspended rat soleus muscle. Eur J Appl Physiol 70: 528-535, 1995.

CHAMBERLAIN S, LEWIS DM: Contractile characteristics and innervation ratio of rat soleus motor units. $J$ Physiol Lond 412: 1-21, 1989. 
D'ALBIS A, COUTEAUX R, JANMOT C, MIRA JC: The same myosin isoforms are found in the female and male sexually dimorphic levator ani muscle of the rat, but their postnatal transitions are not synchronous. FEBS Lett 278: 41-44, 1991.

DESPLANCHES D, MAYET MH, SEMPORE B, FLANDROIS R: Structural and functional responses to prolonged hindlimb suspension in rat muscle. $J$ Appl Physiol 63: 558-563, 1987.

EGGINTON S: Numerical and areal density estimates of fibre type composition in a skeletal muscle (rat extensor digitorum longus). $J$ Anat 168: 73-80, 1990.

EISEN A, KARPATI G, CARPENTER S: Reserpine induced alteration of physiological properties and histochemical fiber types in rat skeletal muscle. Exp Neurology 46: 554-565, 1975.

GILLESPIE MJ, GORDON T, MURPHY PR: Motor units and histochemistry in rat lateral gastrocnemius and soleus muscles: evidence for dissociation of physiological and histochemical properties after reinnervation. J Neurophysiol 57: 921-937, 1987.

GREEN HJ, KLUG GA, REICHMANN H, SEEDORF U, WIEHRER W, PETTE D: Exercise-induced fibre type transitions with regard to myosin, parvalbumin, and sarcoplasmic reticulum in muscles of the rat. Pflugers Arch 400: 432-438, 1984.

GUTH L, SAMAHA FJ: Procedure for the histochemical demonstration of actomyosin ATPase. Exp Neurol 28: 365367, 1970.

HALL-CRAGGS EC, MAX SR, WINES MM, MORELAND TM, HEBEL JR: Central core degeneration after tenotomy in soleus muscles of hyperthyroid rats. Exp Neurol 81: 722-732, 1983.

HÄMÄLÄINEN N, PETTE D: The histochemical profiles of fast fiber types IIB, IID, and IIA in skeletal muscles of mouse, rat, and rabbit. J Histochem Cytochem 41: 733-743, 1993.

HERBISON GJ, JAWEED MM, DITUNNO JF, SCOTT CM: Effect of overwork during reinnervation of rat muscle. Exp Neurol 41: 1-14, 1973.

HERBISON GJ, JAWEED MM, DITUNNO JF: Recovery of reinnervating rat muscle after cast immobilization. Exp Neurol 85: 239-248, 1984.

HO KW, HEUSNER WW, VAN HUSS J, VAN HUSS WD: Postnatal muscle fibre histochemistry in the rat. $J$ Embryol Exp Morphol 76: 37-49, 1983.

IANUZZO D, PATEL P, CHEN V, O'BRIEN P, WILLIAMS C: Thyroidal trophic influence on skeletal muscle myosin. Nature 270: 74-76, 1977.

IANUZZO D, PATEL P, CHEN V, O'BRIEN P: A possible thyroidal trophic influence on fast and slow skeletal muscle myosin. In: Plasticity of Muscle. D. PETTE (ed), Walter de Gruyter, New York, 1980, pp 593-605.

ITOH M, ITOH K, TAGUCHI S, HIROFUJI C, TAKEUCHI H, ISHIHARA A: Effects of hypobaric hypoxia on fiber type composition of the soleus muscle in the developing rat. Aviat Space Environ Med 63: 583-587, 1992.

JAWEED MM, HERBISON GJ, DITUNNO JF: Denervation and reinnervation of fast and slow muscles. A histochemical study in rats. $J$ Histochem Cytochem 23: 808-827, 1975.

JOUMAA WH, LÉOTY C: A comparative analysis of the effects of exercise training on contractile responses in fastand slow-twitch rat skeletal muscles. J Comp Physiol B 172: 329-338, 2002.

KOVANEN V, SUOMINEN H: Effects of age and life-time physical training on fibre composition of slow and fast skeletal muscle in rats. Pflugers Arch 408: 543-551, 1987.

KRAEMER WJ, STARON RS, GORDON SE, VOLEK JS, KOZIRIS LP, DUNCAN ND, NINDL BC, GÓMEZ AL, MARX JO, FRY AC, MURRAY JD: The effects of 10 days of spaceflight on the shuttle Endeavor on predominantly fast-twitch muscles in the rat. Histochem Cell Biol 114: 349-355, 2000.

KUGELBERG E: Adaptive transformation of rat soleus motor units during growth. J Neurol Sci 27: 269-289, 1976.

LARSSON L, YU F: Gender-related differences in the regulatory influence of thyroid hormone on the expression of myosin isoforms in young and old rats. Acta Physiol Scand 159: 81-89, 1997.

LARSSON L, LI X, TERESI A, SALVIATI G: Effects of thyroid hormone on fast- and slow- twitch skeletal muscles in young and old rats. $J$ Physiol Lond 481: 149-161, 1994.

LEWIS DM, LEVI AJ, BROOKSBY P, JONES JV: A faster twitch contraction of soleus in the spontaneously hypertensive rat is partly due to changed fibre type composition. Exp Physiol 79: 377-386, 1994. 
LI X, HUGHES SM, SALVIATI G, TERESI A, LARSSON L: Thyroid hormone effects on contractility and myosin composition of soleus muscle and single fibres from young and old rats. J Physiol Lond 494: 555-567, 1996.

LIEBER RL, FRIDÉN JO, HARGENS AR, FERINGA ER: Long-term effects of spinal cord transection on fast and slow rat skeletal muscle. II. Morphometric properties. Exp Neurol 91: 435-448, 1986.

LUGINBUHL AJ, DUDLEY GA, STARON RS: Fiber type changes in rat skeletal muscle after intense interval training. Histochemistry 81: 55-58, 1984.

MARTIN WD, ROMOND EH: Effects of chronic rotation and hypergravity on muscle fibers of soleus and plantaris muscles of the rat. Exp Neurol 49: 758-771, 1975.

MIDRIO M, DANIELI-BETTO D, MEGIGHIAN A, VELUSSI C, CATANI C, CARRARO U: Slow-to-fast transformation of denervated soleus muscle of the rat, in the presence of an antifibrillatory drug. Pflugers Arch 420: 446-450, 1992.

MIYABARA EH, AOKI MS, SOARES AG, SALTAO RM, VILICEV CM, PASSARELLI M, SCANLAN TS, GOUVEIA CH, MORISCOT AS: Thyroid hormone receptor-beta-selective agonist GC-24 spares skeletal muscle type I to II fiber shift. Cell Tissue Res 321: 233-241, 2005.

NAKANO H, HAYASHI K, SAITOH A, SAKUMA K, KATSUTA S: Oxidative enzyme activity in the rat soleus muscle and its motoneurons during postnatal maturation. Brain Res Bull 38: 235-238, 1995.

NARUSAWA M: Change in fiber type in partially-denervated soleus muscle of the rat. Tokai J Exp Clin Med 10: 499$507,1985$.

NAYA FJ, MERCER B, SHELTON J, RICHARDSON JA, WILLIAMS RS, OLSON EN: Stimulation of slow skeletal muscle fiber gene expression by calcineurin in vivo. J Biol Chem 275: 4545-4548, 2000.

NIEDERLE B, MAYR R: Course of denervation atrophy in type I and type II fibres of rat extensor digitorum longus muscle. Anat Embryol (Berl) 153: 9-21, 1978.

OISHI Y, YAMAMOTO H, NAGANO M, MIYAMOTO E, FUTATSUKA M: The effects of 2,5-hexanedione and acrylamide on myosin heavy chain isoforms of slow and fast skeletal muscles of the rat. Toxicol Appl Pharm 139: 15-21, 1996.

OZAKI K, MATSUURA T, NARAMA I: Histochemical and morphometrical analysis of skeletal muscle in spontaneous diabetic WBN/Kob rat. Acta Neuropathol 102: 264-270, 2001.

PADYKULA H, HERMAN E: The specificity of the histochemical method for adenosine triphosphate. $J$ Histochem Cytochem 3: 170-195,1955.

PETTE D: Historical Perspectives: plasticity of mammalian skeletal muscle. J Appl Physiol 90: 1119-1124, 2001.

PETTE D: The adaptive potential of skeletal muscle fibers. Can J Appl Physiol 27: 423-448, 2002.

PETTE D, STARON RS: Mammalian skeletal muscle fiber type transitions. Int Rev Cytol 170: 143-223, 1997.

PETTE D, STARON RS: Myosin isoforms, muscle fiber types and transitions. Microsc Res Tech 50: 500-509, 2000.

PETTE D, STARON RS: Transitions of muscle fiber phenotypic profiles. Histochem Cell Biol 115: 359-372, 2001.

POUSSON M, PÉROT C, GOUBEL F: Stiffness changes and fibre type transitions in rat soleus muscle produced by jumping training. Pflugers Arch 419: 127-130, 1991.

PŘENOSIL O, ŽURMANOVÁ J, MALÁČOVÁ D, SOUKUP T: Differentiation of muscle fiber types and expression of myosin heavy chain isoforms in slow and fast rat skeletal muscles - re-evaluated. Physiol Res 57: 26-27, 2008.

PULLEN AH: The distribution and relative size of fibre types in the extensor digitorum longus and soleus muscles of the adult rat. J Anat 123: 467-486, 1977.

PUNKT K, PSINIA I, WELT K, BARTH W, ASMUSSEN G: Effects on skeletal muscle fibres of diabetes and Ginkgo biloba extract treatment. Acta Histochem 101: 53-69, 1999.

RAJIKIN MH: Change of fibre type composition in soleus muscle of male and female rats during postnatal development. Malay Appl Biol 2: 109-113, 1984.

RANVIER L: De quelques faits relatifs à l'histologie et à la physiologie des muscles striés. Arch Physiol Norm Pathol 1: $5,1873$.

SAKUMA K, YAMAGUCHI A, OHMORI H, KATSUTA S: Nonuniform changes in fibre types in the soleus muscle on the developing rat. Eur J Appl Physiol Occup Physiol 70: 132-137, 1995.

SCHIAFFINO S: Fibre types in skeletal muscle: a personal account. Acta Physiol (Oxf) 199: 451-463, 2010. 
SCHIAFFINO S, REGGIANI C: Molecular diversity of myofibrillar proteins: gene regulation and functional significance. Physiol Rev 76: 371-423, 1996.

SIMARD C, LACAILLE M, VALLIERES J: Effects of hypokinesia/hypodynamia on contractile and histochemical properties of young and old rat soleus muscle. Exp Neurol 97: 106-114, 1987.

SMERDU V, SOUKUP T: Demonstration of myosin heavy chain isoforms in rat and humans: the specificity of seven available monoclonal antibodies used in immunohistochemical and immunoblotting methods. Eur J Histochem 52: 179-190, 2008.

SOUKUP T, JIRMANOVÁ I: Regulation of myosin expression in developing and regenerating extrafusal and intrafusal muscle fibers with special emphasis on the role of thyroid hormones. Physiol Res 49: 617-633, 2000.

SOUKUP T, VYDRA J, ČERNÝ M: Changes in ATPase and SDH reactions of the rat extrafusal and intrafusal muscle fibres after preincubations at different $\mathrm{pH}$. Histochemistry 60: 71-84, 1979.

SOUKUP T, ZACHAŘOVÁ G, SMERDU V: Fibre type composition of soleus and extensor digitorum longus muscles in normal female inbred Lewis rats. Acta Histochem 104: 399-405, 2002.

SOUKUP T, SMERDU V, ZACHAŘOVÁ G: Fiber type composition of unoperated rat soleus and extensor digitorum longus muscles after unilateral isotransplantation of a foreign muscle in long-term experiments. Physiol Res 58: 253-262, 2009.

STARON RS, PETTE D: The continuum of pure and hybrid myosin heavy chain-based fibre types in rat skeletal muscle. Histochemistry 100: 149-153, 1993.

STARON RS, KRAEMER WJ, HIKIDA RS, REED DW, MURRAY JD, CAMPOS GE, GORDON SE: Comparison of soleus muscles from rats exposed to microgravity for 10 versus 14 days. Histochem Cell Biol 110: 73-80, 1998.

STARON RS, KRAEMER WJ, HIKIDA RS, FRY AC, MURRAY JD, CAMPOS GE: Fiber type composition of four hindlimb muscles of adult Fisher 344 rats. Histochem Cell Biol 111: 117-123., 1999.

STEPHENSON GMM: Diversity and plasticity of vertebrate skeletal muscle: insights from hybrid fibres. Braz $J$ Morphol Sci 23: 187-194, 2006.

TALMADGE RJ, ROY RR, EDGERTON VR: Persistence of hybrid fibers in rat soleus after spinal cord transection. Anat Rec 255: 188-201, 1999.

THOMAS PE, RANATUNGA KW: Factors affecting muscle fiber transformation in cross-reinnervated muscle. Muscle Nerve 16: 193-199, 1993.

TIAN LM, FENG DP: The interaction of thyroidectomy with spinal cord transection or cross-inervation in their effects on muscle phenotypic characteristics. Chin J Physiol Sci 6: 1-12, 1990.

VADÁSZOVÁ A, ZACHAŘOVÁ G, MACHÁČOVÁ K, JIRMANOVÁ I, SOUKUP T: Influence of thyroid status on the differentiation of slow and fast muscle phenotypes. Physiol Res 53 (Suppl 1): S57-S61, 2004.

VADÁSZOVÁ A, HUDECOVÁ S, KRIŽANOVÁ O, SOUKUP T: Levels of myosin heavy chain mRNA transcripts and content of protein isoforms in the slow soleus muscle of 7-month-old rats with altered thyroid status. Physiol Res 55: 221-225, 2006a.

VADÁSZOVÁ A, HUDECOVÁ S, KRIŽANOVÁ O, SOUKUP T: Levels of myosin heavy chain mRNA transcripts and protein isoforms in the fast extensor digitorum longus muscle of 7-month-old rats with chronic thyroid status alterations. Physiol Res 55: 707-710, 2006b.

VADÁSZOVÁ-SOUKUP A, SOUKUP T: Dual role of thyroid hormones in rat soleus muscle MyHC isoform expression. Physiol Res 56: 833-836, 2007.

VESELY MJ, SANDERS R, GREEN CJ, MOTTERLINI R: Fibre type specificity of haem oxygenase-1 induction in rat skeletal muscle. FEBS Lett 458: 257-260, 1999.

WIGSTON DJ, ENGLISH AW: Fiber-type proportions in mammalian soleus muscle during postnatal development. J Neurobiol 23: 61-70, 1992.

YAMAGUCHI A, SAKUMA K, MORITA I, SOYA H, TAKEDA H, KATSUTA S: Changes in fibre types in rat soleus and plantaris muscles following hypophysectomy and compensatory overload. Acta Physiol Scand 158: 89-95, 1996.

ZACHAŘOVÁ G, KUBÍNOVÁ L: Stereological methods based on point counting and unbiased counting frames for two-dimensional measurements in muscles: comparison with manual and image analysis methods. $J$ Muscle Res Cell Motil 16: 295-302, 1995. 
ZACHAŘOVÁ G, KNOTKOVÁ-URBANCOVÁ J, HNÍK P, SOUKUP T: Nociceptive atrophy of the rat soleus muscle induced by bone fracture: a morphometric study. J Appl Physiol 82: 552-557, 1997.

ZACHAŘOVÁ G, MRÁČKOVÁ K, JIRMANOVÁ I, SOUKUP T: Stereological evaluation of the soleus muscle isografted into fast extensor digitorum longus (EDL) muscle in rats with different thyroid status. Gen Physiol Biophys 18 (Suppl 1): 84-86, 1999.

ZACHAŘOVÁ G, VADÁSZOVÁ A, SMERDU V, ASMUSSEN G, SOUKUP T: The effect of a unilateral muscle transplantation on the muscle fiber type and the MyHC isoform content in unoperated hind limb slow and fast muscles of the inbred Lewis rats. Physiol Res 54: 691-696, 2005.

ŽURMANOVÁ J, MALÁČOVÁ D, PŮTA F, NOVÁK P, Ř́ICCÝ J, SOUKUP T: Mass spectrometry analyses of rat 2b myosin heavy chain isoform. Physiol Res 56: 659-662, 2007.

ŽURMANOVÁ J, PŮTA F, STOPKOVÁ R, Ř́ICCYÝ J, SOUKUP T: The presence of $2 \mathrm{~b}$ and $2 \mathrm{x} / \mathrm{d}$ myosin heavy chain mRNAs in the rat slow soleus muscle confirmed by real time RT-PCR with a newly designed set of primers. Physiol Res 57: 81-82, 2008a.

ŽURMANOVÁ J, PŮTA F, STOPKOVÁ R, SOUKUP T: Real time RT-PCR with newly designed primers confirmed the presence of $2 b$ and $2 x / d$ myosin heavy chain mRNAs in the rat slow soleus muscle. Physiol Res 57: 973$978,2008 b$. 